\title{
Application of New TOPSIS Approach to Identify the Most Significant Risk Factor and Continuous Monitoring of Death of COVID-19
}

\author{
Priyanka Majumder ${ }^{1 \star}$, Piyali Biswas ${ }^{2}$, Srestha Majumder ${ }^{3}$
}

\begin{abstract}
${ }^{1}$ Department of Basic Science and Humanities, Techno College of Engineering Agartala, Maheshkhola-799004, Tripura, INDIA ${ }^{2}$ Department of Physics, National Institute of Technology Agartala, Jirania-799046, Tripura, INDIA

${ }^{3}$ Department of Computer Science Engineering, Techno College of Engineering Agartala, Maheshkhola-799004, Tripura, INDIA *Corresponding Author: majumderpriyanka94@yahoo.com
\end{abstract}

Citation: Majumder P, Biswas P, Majumder S. Application of New TOPSIS Approach to Identify the Most Significant Risk Factor and Continuous Monitoring of Death of COVID-19. Electron J Gen Med. 2020;17(6):em234. https://doi.org/10.29333/ejgm/7904

\begin{tabular}{|c|c|}
\hline ARTICLE INFO & ABSTRACT \\
\hline Received: 5 Apr. 2020 & A pandemic is a disease that spreads across a large area like multiple continents or worldwide. More than 211 \\
\hline Accepted: 6 Apr. 2020 & $\begin{array}{l}\text { nations are already affected by Covid-19. The World Health Organization (WHO) on } 11 \text { March } 2020 \text { declared Covid- } \\
19 \text { a pandemic. There are more than } 1,282,931 \text { cases of the coronavirus illness over } 211 \text { countries and territories } \\
\text { around the world. Currently coronavirus has no proper treatment in Medical Science, increasing the number of } \\
\text { affected people day by day with the number of cases worldwide of novel coronavirus surpassing } 1,282,931 \text {, with } \\
\text { some } 72,616 \text { deaths approximately. That is why the main objective of the present investigation is to identify the } \\
\text { significant risk factor. Also, in this study we are continuously monitoring the spread of coronavirus. In this study } \\
\text { we use a new TOPSIS MCDM approach and GMDH apply to select the significant risk factor and continuous } \\
\text { monitoring of death due to Covid-19. Result indicates that "contamination due to contact with the infected } \\
\text { person" is the main responsible factor behind the pandemic COVID-19. Also, in this investigation we get an optimal }\end{array}$ \\
\hline
\end{tabular}

Keywords: Coronavirus, risk factor, continuous death monitoring, new TOPSIS approach, GMDH

\section{INTRODUCTION}

In the world of 2020, where WHO has declared Covid-19 to be Pandemic (1), where there is chaos everywhere, people are quarantined, the times square is empty, and so are the other crowded places, where one can find anybody wearing a mask, and with a fear in their eyes-we are literally living through the pages of history books of the future days.

Coronavirus has horribly spread across the stretches of the world and too many people are suffering. It's declared Pandemic by WHO as it is a disease that people are not immune to, spreading throughout the world beyond expectation. Almost 211 countries are suffering (2). More than 72,616 people across the world have lost their lives, and thousands of people are fighting everyday for their lives (2). Countries all over the world are declaring Health emergencies and taking whatever possible steps to keep the citizens safe (3).

As the virus is spreading beyond the borders of the countries, we try looking for any possible escape route. Medical Science is doing its best in the search of a possible solution. Doctors and medical staffs all over the world have truly proved themselves to be the unsung hero in this time of chaos by putting themselves in the front line, and by making sacrifices for the sake of humanity (4). So while being in the non-medical field, we still have tried to do our part by trying to contribute a little in the quest. Through the data we have collected do far from Literature surveys, Media websites and by taking medical suggestions, we have chosen three major cause of the spread of Covid-19. It's mainly spreading through Verbal contamination, contamination through eatables, and contamination due to contact with the infected person. Since we know about quarantine, a situation where a person is asked to isolate or distant himself from crowded places in order to have a safe distance from everyone else, so that there is not contact between him and the outside world, we understand how Contamination through one person to another is taken seriously. Countries all over the world are declaring to keep the schools, colleges closed, to keep down the social gatherings, and suggesting to stay at home. This is very much important not only for others, and for ourselves as well. People are also asked to keep on wearing a mask, to wash their hands again and again. Here hygiene becomes an important thing. The risk factors are leading to panic among the people, creating more chaos as a result. So, our main object of this study to identify the most significant risk factors behind the spread of Coronavirus. Using Multi Criteria Decision Making (MCDM) technique we select that significant risk factor of COVID-19.

Multi Criteria Decision Making (MCDM) is most important branch of Operation Research by which people take their complex decision daily life. There are many MCDM tools are modelled by so many researchers. All this MCDM Models are based on behaviour of the decision-making problem. In MCDM process people select the best alternatives with respect to certain criteria. Recently this MCDM tools are used in Economical, Social, Environmental etc (5-7). In MCDM 
techniques some methods give priority value and some methods give rank of indicators.

One of the ranking based MCDM tool is Technique for Order Preference by Similarity to an Ideal Solution (TOPSIS) which is proposed by Hwang and Yoon in 1981 (8). The logic behind computational process is easy to understand. The main phase of this method is to find the minimum metric from the bestperforming solution (the best case) and the maximum distance from each of the worst-performing solution (the worst case) (9). Factors have only a negative or positive side. The positive aspect of a factor is profit, and expense is the negative aspect. So, decision maker easily determines the ideal solution. In this way, identify the best value from positive ideal solution, and the worst value from negative ideal solution (10). The outcome value of these two metrics is conveyed in terms of a closeness coefficient, which is depends on the fact that the alternatives with a numerical value of a larger coefficient of attraction is known as the preferred alternative (10). This TOPSIS method has consisted eight stages (11).

From the previous discussion it is clear that, TOPSIS method is based on the concept of best alternatives should have the shortest distance and maximum distance (12). Shortest distance measured in TOPSIS by Euclidean distance (8). But Euclidean metric always does not give shortest distance between two points. Supremum metric always gives the better result from Euclidean distance in shortest distance in any dimensional problem. Theorem 1 represents that distance measure by Supremum metric is always less than equal to distance measure by Euclidean metric. In this theorem $d_{\infty}$ and $d$ denote Supremum and Euclidean metric respectively.

Theorem: Let $d_{\infty}, d: \mathbb{R}^{n} \times \mathbb{R}^{n} \rightarrow R^{+} \cup\{0\}$ define by $d(x, y)=\sqrt{\sum_{i=1}^{n}\left(x_{i}-y_{i}\right)^{2}} \quad$ and $\quad d_{\infty}(x, y)=\max \left\{\mid x_{i}-\right.$ $\left.y_{i} \mid: x_{i}, y_{i} \in \mathbb{R}\right\}$ then $d(x, y) \leq d_{\infty}(x, y)$ for all $x=$ $\left(x_{1}, x_{2}, \ldots, x_{n}\right)$ and $y=\left(y_{1}, y x_{2}, \ldots, y_{n}\right)$ belongs to $\mathbb{R}^{n}$.

Proof: Let $x=\left(x_{1}, x_{2}, \ldots, x_{n}\right)$ and $y=\left(y_{1}, y x_{2}, \ldots, y_{n}\right)$ be two elements of $\mathbb{R}^{n}$.

$$
\begin{aligned}
& \text { Then }\left|x_{i}-y_{i}\right|=\sqrt{\left(x_{i}-y_{i}\right)^{2}} \text { for all } x_{i}, y_{i} \in \mathbb{R} \\
& \text { This implies }\left|x_{i}-y_{i}\right| \leq \sqrt{\sum_{i=1}^{n}\left(x_{i}-y_{i}\right)^{2}} \text { for all } x_{i}, y_{i} \in \mathbb{R} \\
& \text { So } \max \left\{\left|x_{i}-y_{i}\right|: i=1,2, \ldots, n\right\} \leq \sqrt{\sum_{i=1}^{n}\left(x_{i}-y_{i}\right)^{2}} \\
& \text { Hence } d(x, y) \leq d_{\infty}(x, y) \text { for all } \mathrm{x}, \mathrm{y} \in \mathbb{R}^{n}
\end{aligned}
$$

\section{Objective of the Present Study}

This study consists of multiple objectives. The objectives of the present study are

(i) Identify the most significant risk factor of COVID-19. So, in this study we used new TOPSIS approach. Because in TOPSIS method shortest distance use to find the ideal solution measured by Euclidean distance $(d(x, y))$ (8). From the above theorem 1 it is clear that supremum or maximum distance $\left(d_{\infty}(x, y)\right)$ always less than equal to Euclidean distance. So, in existing TOPSIS method we replace Euclidean distance by supremum distance for ideal solution. Also, since the greatest distance used for negative-ideal solution and supremum distance always give less than from Euclidean distance so for non-ideal solution used Euclidean distance.

(ii) In recent years, due to the Verbal contamination along with contamination through eatables, and contamination due to contact with the infected person the patient of Coronavirus increases day by day. But it has no Proper solution in Medical Science. So, death is also increasing. In the present study we are trying to predict the death of infected person. But in this study, we do not consider age of infected people because it has no proper treatment. Thus, in the current study, a new approach was made for the proposed of a continuous monitoring of death from confirmed case of Coronavirus by New TOPSIS approach and Group Method of Data Handling (GMDH) based predictive model.

(iii) Second object of this investigation is Compare the result of new approach of TOPSIS with existing TOPSIS method.

\section{Scientific Benefits of the Study}

The benefits of the proposed model have been covered by the objectivity and flexibility of the techniques. This new model depends on the method becomes more accurate and consistent compared to existing regression models. Since the weight given to the factors is absent in the new predictive model so death from infected cases of unbiased assessment of Coronavirus is possible.

\section{Novelty of the Study}

The novelties of the present investigation are

(i) First time supremum metric is used for ideal solution in TOPSIS method.

(ii) Second novelty is new TOPSIS approach applies for selection of most significant risk factor of COVID-19.

(iii) Continuous monitoring of death assessment of Coronavirus is another novelty of this investigation.

In the next section, data collection is discussed.

\section{DATA COLLECTION}

Data was collected from the website of World Health Organization (WHO) (13) and some Government report of different countries. Table 1 shows the normalized data of confirmed and death case from 31-Dec-2019 to 05-Apr-2020. Next section describes new TOPSIS approach and GMDH. In this study data are normalized by formula of $\bar{z}_{i}=\frac{z_{i}}{\sum_{i=1}^{k} z_{i}}$, Where $z_{i}, \bar{z}_{i}$ and $k$ denote the actual data, normalized data and total number of date respectively.

Table 1. Data of Total Confirmed and New Confirmed case from 31 December 2019 to 05 April 2020

\begin{tabular}{lcc}
\hline Date & $\begin{array}{c}\text { Total confirmed cases } \\
\text { of COVID-19 }\end{array}$ & $\begin{array}{c}\text { Total confirmed deaths due } \\
\text { to CoVID-19 }\end{array}$ \\
\hline 31-Dec-19 & $1.82 \mathrm{E}-06$ & 0 \\
\hline 01-Jan-20 & $1.82 \mathrm{E}-06$ & 0 \\
\hline 02-Jan-20 & $1.82 \mathrm{E}-06$ & 0 \\
\hline 03-Jan-20 & $2.97 \mathrm{E}-06$ & 0 \\
\hline 04-Jan-20 & $2.97 \mathrm{E}-06$ & 0 \\
\hline 05-Jan-20 & $3.98 \mathrm{E}-06$ & 0 \\
\hline 06-Jan-20 & $3.98 \mathrm{E}-06$ & 0 \\
\hline 07-Jan-20 & $3.98 \mathrm{E}-06$ & 0 \\
\hline 08-Jan-20 & $3.98 \mathrm{E}-06$ & 0 \\
\hline 09-Jan-20 & $3.98 \mathrm{E}-06$ & 0 \\
\hline 10-Jan-20 & $3.98 \mathrm{E}-06$ & $1.53 \mathrm{E}-06$ \\
\hline 11-Jan-20 & $3.98 \mathrm{E}-06$ & $1.53 \mathrm{E}-06$ \\
\hline 12-Jan-20 & $3.98 \mathrm{E}-06$ & $1.53 \mathrm{E}-06$ \\
\hline 13-Jan-20 & $4.05 \mathrm{E}-06$ & $1.53 \mathrm{E}-06$ \\
\hline 14-Jan-20 & $4.05 \mathrm{E}-06$ & $3.06 \mathrm{E}-06$ \\
\hline 15-Jan-20 & $4.12 \mathrm{E}-06$ & $3.06 \mathrm{E}-06$ \\
\hline 16-Jan-20 & $4.12 \mathrm{E}-06$ & \\
\hline
\end{tabular}


Table 1 (continued). Data of Total Confirmed and New Confirmed case from 31 December 2019 to 05 April 2020

\begin{tabular}{|c|c|c|}
\hline Date & $\begin{array}{c}\text { Total confirmed cases } \\
\text { of COVID-19 }\end{array}$ & $\begin{array}{c}\text { Total confirmed deaths due } \\
\text { to COVID-19 }\end{array}$ \\
\hline 17-Jan-20 & $4.46 \mathrm{E}-06$ & $3.06 \mathrm{E}-06$ \\
\hline 18-Jan-20 & $5.6 \mathrm{E}-06$ & $3.06 \mathrm{E}-06$ \\
\hline 19-Jan-20 & $1.48 \mathrm{E}-05$ & $4.58 \mathrm{E}-06$ \\
\hline 20-Jan-20 & $1.61 \mathrm{E}-05$ & $4.58 \mathrm{E}-06$ \\
\hline 21-Jan-20 & $2.65 \mathrm{E}-05$ & $9.17 \mathrm{E}-06$ \\
\hline 22-Jan-20 & $3.61 \mathrm{E}-05$ & $2.6 \mathrm{E}-05$ \\
\hline 23-Jan-20 & 4.26E-05 & $2.6 \mathrm{E}-05$ \\
\hline 24-Jan-20 & $6.06 \mathrm{E}-05$ & 3.97E-05 \\
\hline 25-Jan-20 & $9.12 \mathrm{E}-05$ & $6.26 \mathrm{E}-05$ \\
\hline 26-Jan-20 & 0.000137 & $8.55 \mathrm{E}-05$ \\
\hline 27-Jan-20 & 0.00019 & 0.000124 \\
\hline 28-Jan-20 & 0.00031 & 0.000162 \\
\hline 29-Jan-20 & 0.00041 & 0.000202 \\
\hline 30-Jan-20 & 0.000528 & 0.00026 \\
\hline 31-Jan-20 & 0.000664 & 0.000325 \\
\hline 01-Feb-20 & 0.000807 & 0.000396 \\
\hline 02-Feb-20 & 0.000983 & 0.000466 \\
\hline 03-Feb-20 & 0.001173 & 0.000553 \\
\hline 04-Feb-20 & 0.001392 & 0.000652 \\
\hline 05-Feb-20 & 0.001656 & 0.000753 \\
\hline 06-Feb-20 & 0.001909 & 0.000863 \\
\hline 07-Feb-20 & 0.002127 & 0.000975 \\
\hline 08-Feb-20 & 0.002359 & 0.001106 \\
\hline 09-Feb-20 & 0.002536 & 0.001242 \\
\hline $10-$ Feb-20 & 0.002738 & 0.00139 \\
\hline $11-F e b-20$ & 0.002911 & 0.001555 \\
\hline $12-F e b-20$ & 0.003051 & 0.001703 \\
\hline 13-Feb-20 & 0.004074 & 0.002093 \\
\hline 14-Feb-20 & 0.004358 & 0.002113 \\
\hline $15-F e b-20$ & 0.004531 & 0.002333 \\
\hline 16 -Feb-20 & 0.004677 & 0.002549 \\
\hline $17-$ Feb-20 & 0.004817 & 0.002711 \\
\hline $18-F e b-20$ & 0.004952 & 0.002861 \\
\hline 19-Feb-20 & 0.005077 & 0.003073 \\
\hline $20-F e b-20$ & 0.005113 & 0.003251 \\
\hline $21-F e b-20$ & 0.005181 & 0.003432 \\
\hline $22-F e b-20$ & 0.005254 & 0.003603 \\
\hline 23-Feb-20 & 0.005322 & 0.003762 \\
\hline 24-Feb-20 & 0.005358 & 0.004001 \\
\hline 25 -Feb-20 & 0.005411 & 0.004121 \\
\hline $26-F e b-20$ & 0.005469 & 0.004219 \\
\hline $27-F e b-20$ & 0.005544 & 0.004277 \\
\hline 28 -Feb-20 & 0.005629 & 0.004364 \\
\hline 29-Feb-20 & 0.005754 & 0.004462 \\
\hline 01-Mar-20 & 0.005877 & 0.004551 \\
\hline 02-Mar-20 & 0.006015 & 0.004653 \\
\hline 03-Mar-20 & 0.006122 & 0.004763 \\
\hline 04-Mar-20 & 0.006285 & 0.004891 \\
\hline 05-Mar-20 & 0.006436 & 0.005013 \\
\hline 06-Mar-20 & 0.006629 & 0.005171 \\
\hline 07-Mar-20 & 0.006897 & 0.005328 \\
\hline 08-Mar-20 & 0.007146 & 0.005476 \\
\hline 09-Mar-20 & 0.007407 & 0.005826 \\
\hline 10-Mar-20 & 0.007714 & 0.006145 \\
\hline 11-Mar-20 & 0.008009 & 0.006556 \\
\hline 12-Mar-20 & 0.008475 & 0.007054 \\
\hline 13-Mar-20 & 0.009039 & 0.00759 \\
\hline 14-Mar-20 & 0.009672 & 0.008259 \\
\hline 15-Mar-20 & 0.010221 & 0.0088 \\
\hline $16-$ Mar-20 & 0.011305 & 0.009938 \\
\hline 17-Mar-20 & 0.012161 & 0.010849 \\
\hline 18-Mar-20 & 0.013157 & 0.012054 \\
\hline 19-Mar-20 & 0.014393 & 0.013507 \\
\hline 20-Mar-20 & 0.016366 & 0.015097 \\
\hline
\end{tabular}

Table 1 (continued). Data of Total Confirmed and New Confirmed case from 31 December 2019 to 05 April 2020

\begin{tabular}{ccc}
\hline Date & $\begin{array}{c}\text { Total confirmed cases } \\
\text { of COVID-19 }\end{array}$ & $\begin{array}{c}\text { Total confirmed deaths due } \\
\text { to COVID-19 }\end{array}$ \\
\hline 21-Mar-20 & 0.018307 & 0.017183 \\
\hline 22-Mar-20 & 0.020604 & 0.019765 \\
\hline 23-Mar-20 & 0.022833 & 0.022301 \\
\hline 24-Mar-20 & 0.02552 & 0.024995 \\
\hline 25-Mar-20 & 0.028149 & 0.028356 \\
\hline 26-Mar-20 & 0.031606 & 0.032062 \\
\hline 27-Mar-20 & 0.035639 & 0.036157 \\
\hline 28-Mar-20 & 0.039956 & 0.041225 \\
\hline 29-Mar-20 & 0.044357 & 0.046512 \\
\hline 30-Mar-20 & 0.048306 & 0.051286 \\
\hline 31-Mar-20 & 0.052523 & 0.056933 \\
\hline 01-Apr-20 & 0.057487 & 0.063981 \\
\hline 02-Apr-20 & 0.062695 & 0.071616 \\
\hline 03-Apr-20 & 0.067544 & 0.07869 \\
\hline 04-Apr-20 & 0.073068 & 0.088813 \\
\hline 05-Apr-20 & 0.079321 & 0.098374 \\
\hline
\end{tabular}

\section{METHOD USED}

The main objective of the present study is to identify the most significant risk factor of Coronavirus. So in the present study we developed a new approach of TOPSIS MCDM. Also another aim of the present investigation is real time monitoring of spread of this virus. For continuous monitoring we use GMDH. In sub-section "New TOPSIS Approach" and "Group Method of Data Handling (GMDH)" describe the New TOPSIS Approach and GMDH.

\section{New TOPSIS Approach}

The main aim of this present study to develop an existing ranking based MCDM techniques. The existing MCDM technique is TOPSIS. Existing TOPSIS method, shortest distance is required to find ideal solution which is measured by Euclidean metric. But Euclidean metric between any two points always give greater than or equal to supremum metric. So, in the present study we replace Euclidean metric by supremum metric for ideal solution. The name of this new TOPSIS method is TOPSIS 1.

\section{Metric space}

Let $X$ be a non-empty set and a mapping $d: X \times X \rightarrow$ $R^{+} \cup\{0\}$. Then the function $d$ is a metric (or distance) on $X$ if $\mathrm{d}$ satisfies following condition:

(i) Non-negativeness: Distance between any two points of $X$ always non-negative

i.e., for every pair $(\mathrm{x}, \mathrm{y}) \in X \times X, d(\mathrm{x}, \mathrm{y}) \in R^{+} \mathrm{U}\{0\}$

(ii) Identification: Distance between two points of $X$ is vanishing if and only if that two points are equal.

i.e., $d(\mathrm{x}, \mathrm{y})=0$ iff $\mathrm{x}-\mathrm{y}=0$, if $(\mathrm{x}, \mathrm{y}) \in X \times X$

(iii) Symmetry: If $\mathrm{x}, \mathrm{y} \in X$ then distance between $\mathrm{x}$ and $\mathrm{y}$ is equal to $\mathrm{y}$ and $\mathrm{x}$.

i.e., for all $\mathrm{x}, \mathrm{y} \in X$ then $d(\mathrm{x}, \mathrm{y})=d(\mathrm{y}, \mathrm{x})$

(iv) Triangular inequality: Three points of $X$ always satisfy triangular inequality under the function $d$.

i.e., $d(\mathrm{x}, \mathrm{z}) \leq d(\mathrm{x}, \mathrm{y})+d(\mathrm{y}, \mathrm{z})$ for all $\mathrm{x}, \mathrm{y} \in X$

Then the pair $(X, d)$ is called metric space. 


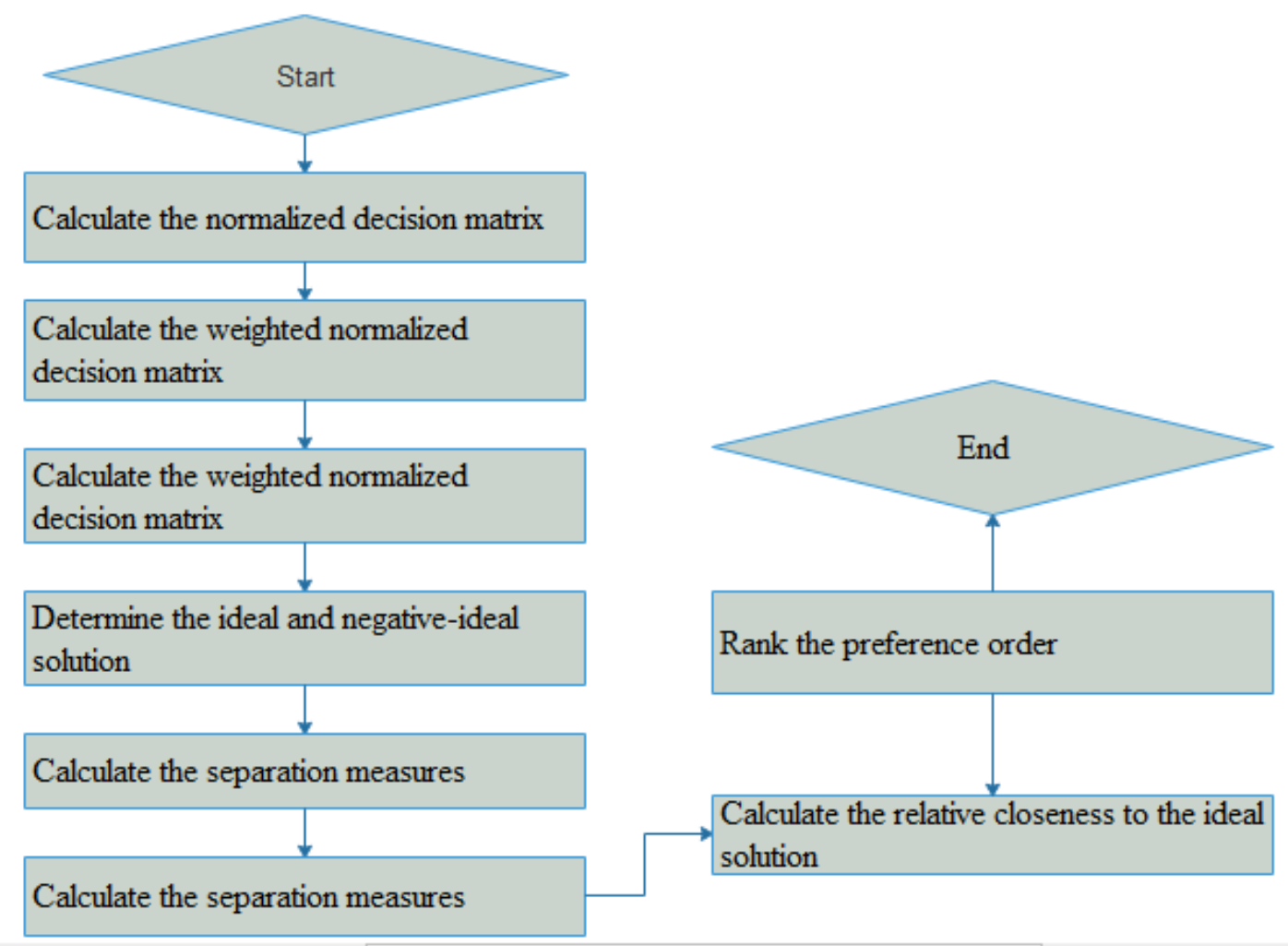

Figure 1. Flow char of TPSIS 1 method

Let $d: \mathbb{R}^{n} \times \mathbb{R}^{n} \rightarrow R^{+} \cup\{0\}$ define by $d(x, y)=$ $\sqrt{\sum_{i=1}^{n}\left(x_{i}-y_{i}\right)^{2}} \quad$ where $x=\left(x_{1}, x_{2}, \ldots, x_{n}\right)$ and $y=$ $\left(y_{1}, y_{2}, \ldots, y_{n}\right)$.

In the study (8) it was found that this $d$ is a metric space. This metric is called Euclidean distance.

Also another function $d_{\infty}: \mathbb{R}^{n} \times \mathbb{R}^{n} \rightarrow R^{+} \cup\{0\}$ define by $d_{\infty}(x, y)=\max \left\{\left|x_{i}-y_{i}\right|: x_{i}, y_{i} \in \mathbb{R}\right\} \quad$ where $\quad x=$ $\left(x_{1}, x_{2}, \ldots, x_{n}\right)$ and $y=\left(y_{1}, y x_{2}, \ldots, y_{n}\right)$.

Also $d_{\infty}$ form a metric in $\mathbb{R}^{n}$. This metric is called supremum distance.

\section{TOPSIS-I}

There is only one difference between TOPSIS and TOPSIS-I. Here we only change the distance formula for ideal soluation. One of the multiple criteria approaches is Technique for Order Preference by Similarity to an Ideal Solution (TOPSIS) by which analyzing decisions for alternatives. The concept of TOPSIS is rational and understandable, and the computation involved is uncomplicated. Moreover, the inherent difficulty of assigning reliable subjective preferences to the criteria is worth noting (9). Figure 1 represents the flow chart of TPSIS 1 method. TOPSIS-I decision making basically based on six impotent steps:

(i) Calculate the normalized decision matrix.

Consider the number of alternatives is $\mathrm{m}$. Let normalized decision matrix $D=\left[r_{i j}\right]_{m \times m}$

The normalized value rij is defined by

$$
r_{i j}=\frac{x_{i j}}{\sqrt{\sum_{i=1}^{m} x_{i j}^{2}}}, \forall i, j
$$

(ii) Calculate the weighted normalized decision matrix. The weighted normalized value $v_{i j}$ is calculated as

$$
v_{i j}=w_{j} r_{i j}, \forall i, j
$$

Where $w_{j}$ is the weight of the jth criterion, and $\sum_{i=1}^{n} w_{j}=1$

(iii) Determine the ideal and negative-ideal solution:

$A^{+}=\left\{v_{1}^{+}, v_{2}^{+}, v_{3}^{+}, \ldots, v_{m}^{+}\right\}=\left\{\left(\max _{i} v_{i j} \mid j \in C_{b}\right),\left(\min _{i} v_{i j} \mid j \in C_{c}\right)\right\}$

$A^{-}=\left\{v_{1}^{-}, v_{2}^{-}, v_{3}^{-}, \ldots, v_{m}^{-}\right\}=\left\{\left(\min _{i} v_{i j} \mid j \in C_{b}\right),\left(\max _{i} v_{i j} \mid j \in C_{c}\right)\right\}$

Where $C_{b}$ is associated with benefit criteria and $C_{c}$ is associated with cost criteria.

(iv) Calculate the separation measures, using the $\mathrm{m}$ dimensional supremum distance. In TOPSIS we calculate separation measures by Euclidean distance. The separation of each alternative and negative from the ideal solution is given as:

$$
\begin{gathered}
S_{i}^{+}=\max \left\{\left|v_{i j}-v_{j}^{+}\right|: j=1,2, \ldots, m\right\}, \forall i \\
S_{i}^{-}=\sqrt{\sum_{j=1}^{m}\left(v_{i j}-v_{j}^{-}\right)^{2}}, \forall i
\end{gathered}
$$

(v) Calculate the relative closeness to the ideal solution: The relative closeness of the alternative $A_{i}$ with respect to $A^{-}$is defined as

$$
R C_{i}^{*}=\frac{S_{i}^{-}}{S_{i}^{-}+S_{i}^{+}}, \forall i
$$

(vi) Rank the preference order. The index values of $R C_{i}^{*}$ lie between 0 and 1 . The larger index value means the closer to ideal solution for alternatives.

\section{Group Method of Data Handling (GMDH)}

The GMDH model is one of the learning machine approaches based on the polynomial theory of complex systems, designed by Ivakhnenko. From this network, the most significant input parameters, number of layers, number of neurons of middle layers, and optimal topology design of the 
network are defined automatically. Therefore, the GMDH network is a self-organized model of active neurons. The structure of the GMDH network is configured thorough the training stage with a polynomial model which produces the minimum error between the predicted value and observed output.

The neuro-fuzzy GMDH network is a very flexible algorithm, and can be hybridized easily by other iterative and evolutionary algorithms (14). The GMDH neural network is a self-organizing, unidirectional structure with multiple layers, each of which is composed of several neurons that have a similar structure. The selection of model criterion in line with the target of modelling and information division, GMDH will confirm the model automatically. If different forms of input units are used, this modelling mechanism will produce different types of models. This automatic modelling mechanism has been successfully applied to build Bayesian networks (15) and Mamdani-type fuzzy models (16).

The main purpose of the GMDH network is actually to construct a function in a feed-forward network on the basis of a second-degree transfer function. The number of layers and neurons within the hidden layers, the effective input variables and the optimal model structure are automatically determined in this algorithm. The mapping between the input and output variables done through a GMDH neural network is a nonlinear function called the Volterra series, in the form of equation (1). The Volterra series as a two-variable second-degree polynomial is analyzed using Equation (2).

$$
\begin{aligned}
& \hat{y}=a_{0}+\sum_{i=1}^{m} a_{i} x_{i}+\sum_{i=1}^{m} \sum_{j=1}^{m} a_{i j} x_{i} x_{j}+\sum_{i=1}^{m} \sum_{j=1}^{m} \sum_{k=1}^{m} x_{j} a_{i j k} x_{i} x_{j} x_{k} \\
& G\left(x_{i} x_{j}\right)=a_{0}+a_{1} x_{i}+a_{2} x_{j}+a_{3} x_{i}^{2}+a_{1} x_{j}^{2}+a_{5} x_{i} x_{j}
\end{aligned}
$$

The aim of the GMDH algorithm is to find the $a_{i}$ unknown coefficients in the Volterra series. The $a_{i}$ coefficients are solved with regression methods for each pair of $x_{i} a$ nd $x_{j}$ input variables (17). On this basis, taking into consideration the principle of least squares error (18), the $\mathrm{G}$ function is defined as follows in equation (3):

$$
E=\frac{\sum_{i=1}^{M}\left(y_{i}-G_{i} O\right)^{2}}{M}
$$

Where $y_{i}=f\left(x_{i 1}, x_{i 2}, x_{i 3}, \ldots \ldots x_{i m}\right), i=1,2,3, \ldots . m$

The Artificial Neural Network (ANN) based model has three parameters which must be estimated properly to produce a reliable model for prediction. The parameters are the topology of the network, value of the weights of the connections and type of activation function. Generally, the trial and error method or some cognitive search algorithms like GA, PSO are used to find the optimal value of the parameters for which accurate prediction can be possible.

But the problem with this method is a sufficient amount of iterations along with many different algorithms are required to be applied to find the optimal configuration of the parameters. Thus, the amount of storage and sophistication needed to execute such algorithms often discourages its further application and reduces its acceptability as an alternative to conventional models for estimation of highly non-linear variables.

The PNN architecture which follows the GMDH algorithms are self-adaptive and can select the topology for which an optimal model can be developed from the given training data and a preselected fitness function which represents the accuracy of the model predictions. The algorithm also utilizes more than 100 algorithms to estimate the value of the weights of the connections. Here also a fitness function is utilized to adjudge the performance of the algorithms and with the best algorithm value of connection weights are predicted.

That is why a model which uses Polynomial Neural Network (PNN) instead of ANN required less storage and computational infrastructure in developing a model compared to ANN. Thus, this architecture was utilized in the present study to identify the interrelationship between the input and output index so that an automated framework can be developed to estimate location selection potential whenever and wherever a new alternative is identified.

GMDH comes with some drawbacks. First, it tends to generate quite complex polynomials even for relatively simple systems. Second, owing to its limited generic structure (that is quadratic two-variable polynomials), GMDH also tends to produce an overly complex network (model) when it comes to highly nonlinear systems. Third, if there are less than three input variables, GMDH algorithm does not generate a highly versatile structure.

ANN is a computational model composed of many processing elements connected by a variable weight. The networks have layers of parallel elements, known as neurons. The concept of ANN was first introduced in 1943, when Warren McCulloch, a neurophysiologist, and a young mathematician, Walter Pitts, wrote a paper on how neurons might work; they modelled a simple neural network with electrical circuits. In recent years, ANNs have been generally used in many areas, such as control, data compression, forecasting, optimization, pattern recognition, classification, speech and vision (19-22).

The objective function of the ANN model is described by equations (4) and (5).

$$
\begin{aligned}
& h_{m}=f\left(w_{n} x_{n}+b_{j}\right) \\
& y=g\left(\epsilon_{n} h_{n}+b_{k}\right)
\end{aligned}
$$

Where $w_{n}$ is the weight, $x_{n}$ is the input, $b_{j}$ and $b_{k}$ are the bias for the input-to-hidden layer and the hidden-to-output layer, respectively, $h_{n}$ is the hidden layer, and $\epsilon_{n}$ is the weight of the hidden layer. $f$ and $g$ are the activation functions applied in between the input and hidden layers and the hidden and output layers, respectively.

The accuracy of the ANN model depends upon three parameters. The number of hidden layers, the value of the weights, and the type of activation function applied in the Input-Hidden and the Hidden-Output layers. Generally, the trial-and-error method is used to estimate these parameters. However, in recent years, search algorithms such as GA, PSO (23), etc., are applied to identify the value of the parameters for which the optimal accuracy from the ANN model can be achieved. In the next section, methodology of our study is described.

\section{METHODOLOGY}

The main objective of this present study is identifying the most significant risk factor of spread of COVID-19.

Let $E$ (see in equation 6 ) denote the risk of spread of COVID19.

$$
E=f(D, W)
$$




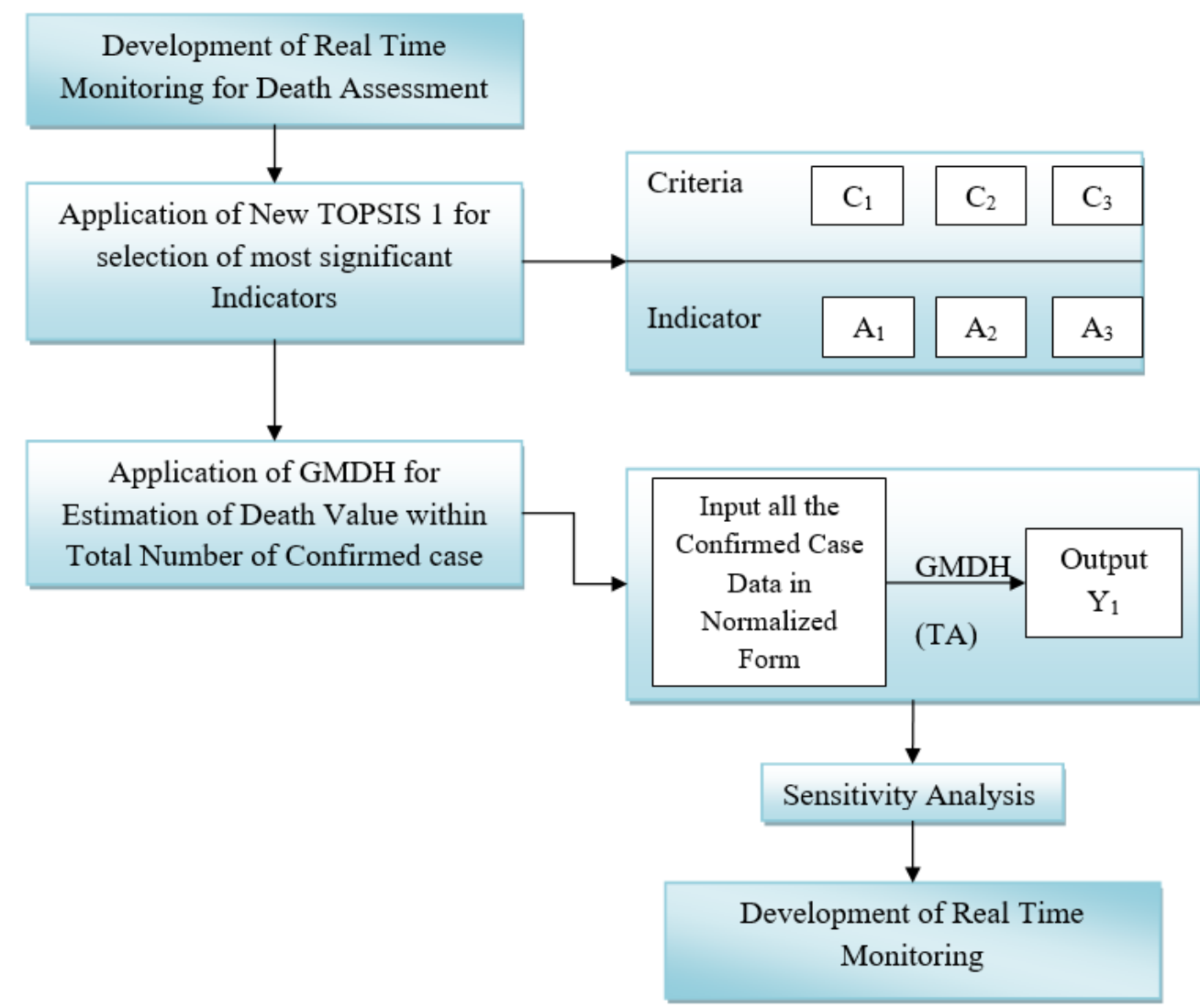

Figure 2. Schematic diagram of the methodology adopted in the present study for estimation sigma index (TA indicates training algorithm. All other abbreviation used in the figure is explained in the text of the paper)

Where $D$ represents the set of collection of all factors of $E$ and $W$ denote the set of priority value of corresponding each factors of $D$.

$$
D=\{m: m=\text { all selected factors }\}
$$

and $W=\{w: w=$ weights all selected factors $\}$

Where $m$ and $w$ represents the selected parameter and its priority value (PV) respectively.

In this present study methodology divided into five pats namely selection of criteria, selection of alternatives, application of TOPSIS 1 method, Application of GMDH and sensitivity analysis, all this subsection discuss according as in the sub-sections "Selection of Criteria", "Selection of Alternatives", "Application of TOPSIS 1 Method", "Application of GMDH" and "Sensitivity Analysis." Figure 2 shows the Schematic diagram of the methodology

\section{Selection of Criteria}

In this present study criteria are selected Literature review, Expert Survey and Media Survey. We studied nearly 40 papers for select the all the risk factors of spread of Coronavirus. In literature it is clearly indicate that why each selected factors are responsible for spread of Coronavirus. So, in this study we select Literature review as important criteria for select the alternatives.

Since our objective is medical issue so in this study experts takes an important role. In this study expert are selects some assistant professor, associate professor and professor of some reputed medical college as well as we take opinion some doctors who are engaged with hospital. Approximately we take nearly 12 experts' opinions for select the risk factors of COVID19.
Media survey is another important criterion to select the factors because they always trying to collect the information about Coronavirus. In this study we use the report of 5 reputed Media for selecting the risk factors.

Let $m$ is a parameter which is select using equation (7) and (8)

$$
\begin{gathered}
m=\text { select, if } n(m)>\left[\frac{p}{2}\right] \\
m=\text { not select, if } n(m) \leq\left[\frac{p}{2}\right]
\end{gathered}
$$

Where $n(m)$ represents the number of literature and $p$ represents the total number of sources. And $[x]$ represents the greatest integer less than equals to $x$.

\section{Selection of Alternatives}

At the second phase of the current procedure, the alternatives selected as indicators that spread Coronavirus. These factors selected by the review of relevant literature followed by selection by a group of experts and Media survey. According to the survey we get Verbal contamination, Contamination due to eatables and contamination due to contact with the infected person are three risk factors of this virus. In this study all these indicators are selected by literature review, expert survey and Media survey. So, in this present study literature review, expert survey and relative of peasant opinions are consider as criteria and denoted by $C_{1}, C_{2}$ and $C_{3}$ respectively. In Table 2 describe all the risk factors of Coronavirus. Figure 3 shows decision hierarchy Structure of our decision problem. 
Table 2. Description of Selected Factors

\begin{tabular}{ll}
\hline Name of Factors & Description \\
\hline Verbal contamination $\left(\mathbf{A}_{\mathbf{1}}\right)$ & $\begin{array}{l}\text { When two people are talking, or if someone sneezes, there are chances that the virus may } \\
\text { spread. And thus, comes the idea of wearing a mask. The infected / suspected person is } \\
\text { specifically asked to keep on the mask. }\end{array}$ \\
\begin{tabular}{ll} 
Contamination due to eatables & $\begin{array}{l}\text { It is said the cold food items, beverages, or ice-cream is to be avoided as the colder temperature } \\
\text { allows the virus to work. With a warmer condition, the virus is unable to do affect much. }\end{array}$ \\
\hline $\begin{array}{l}\left(\mathbf{A}_{\mathbf{2}}\right) \\
\text { Contamination due to contact }\end{array}$ & $\begin{array}{l}\text { With contact with the infected person there is a high chance of spreading of the virus. That's why } \\
\text { with the infected person }\left(\mathbf{A}_{\mathbf{3}}\right)\end{array}$ \\
people are asked to keep safe distances, wash hand often and, for the best, to stay at home.
\end{tabular} \\
\hline
\end{tabular}

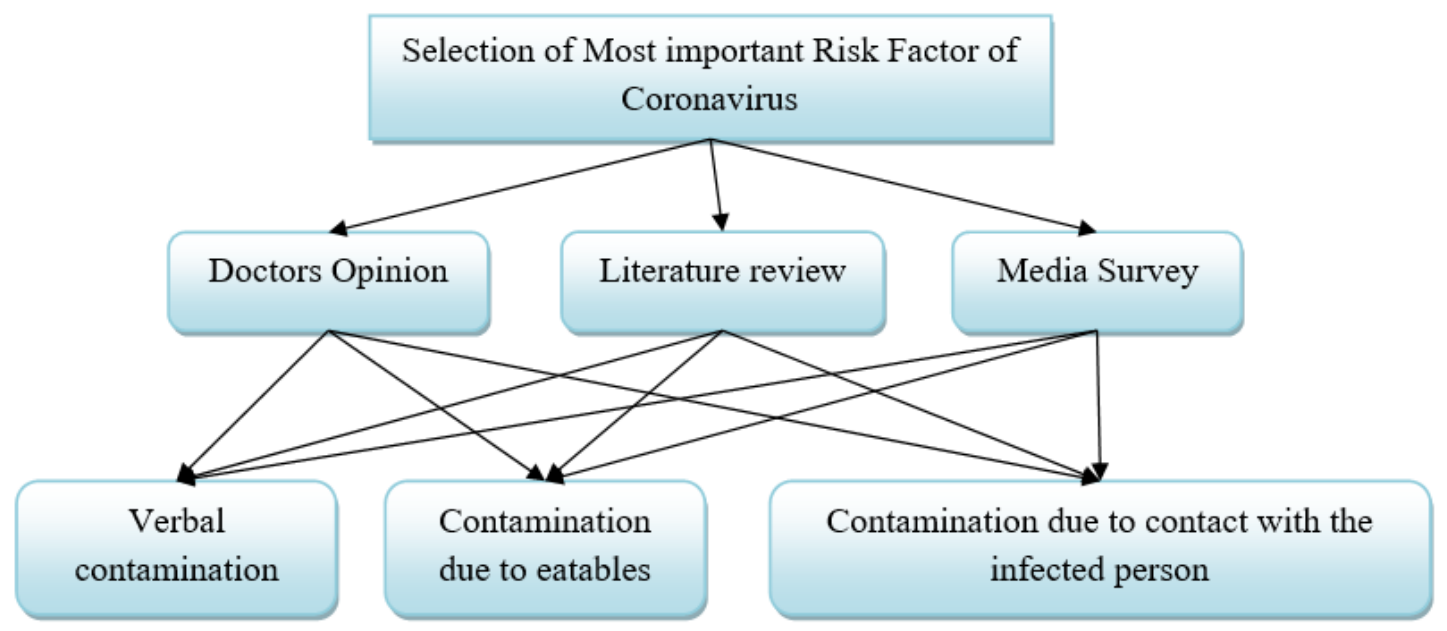

Figure 3. Decision hierarchy Structure

Table 3. 5-point scale

\begin{tabular}{cc}
\hline Name & Score \\
\hline Low (L) & 1 \\
\hline Below Average (BA) & 2 \\
\hline Average (A) & 3 \\
\hline Good (G) & 4 \\
\hline Excellent (E) & 5 \\
\hline
\end{tabular}

Table 4. Score table of alternatives with respect to criteria

\begin{tabular}{cccc}
\hline \multirow{2}{*}{ Alternatives } & \multicolumn{3}{c}{ Criteria } \\
\cline { 2 - 4 } & $\mathrm{C}_{\mathbf{1}}$ & $\mathrm{C}_{\mathbf{2}}$ & $\mathrm{C}_{\mathbf{3}}$ \\
\hline $\mathrm{A}_{1}$ & $\mathrm{G}$ & $\mathrm{E}$ & $\mathrm{G}$ \\
\hline $\mathrm{A}_{2}$ & $\mathrm{BA}$ & $\mathrm{A}$ & $\mathrm{L}$ \\
\hline $\mathrm{A}_{3}$ & $\mathrm{E}$ & $\mathrm{G}$ & $\mathrm{G}$ \\
\hline
\end{tabular}

\section{Application of TOPSIS 1 Method}

In TOPSIS 1 method first find the priority value (PV) of each criterion by any MCDM method. In this study we use Fuzzy AHP MCDM for find the PV of each criteria. Then use TOPSIS 3 MCDM techniques. In this study 5-point scales used for giving relative score. Table 3 represents 5-point scale. In this study relative score of each parameter with respect to each criterion is selected by literature review, expert survey and Media survey. Table 4 represents the relative score with the help of 5-point scale.
Table 5. Score table of alternatives with the help of 5-point scale

\begin{tabular}{cccc}
\hline \multirow{2}{*}{ Alternatives } & \multicolumn{3}{c}{ Criteria } \\
\cline { 2 - 4 } & $\mathbf{C}_{\mathbf{1}}$ & $\mathbf{C}_{\mathbf{2}}$ & $\mathbf{C}_{\mathbf{3}}$ \\
\hline $\mathrm{A}_{1}$ & $x_{11}=4$ & $x_{12}=5$ & $x_{13}=4$ \\
\hline $\mathrm{A}_{2}$ & $x_{21}=2$ & $x_{22}=3$ & $x_{23}=1$ \\
\hline $\mathrm{A}_{3}$ & $x_{31}=5$ & $x_{32}=4$ & $x_{33}=4$ \\
\hline$\sqrt{\sum_{i=1}^{3} x_{i j}^{2}}$ & 6.708203932 & 7.071067812 & 5.744563 \\
\hline
\end{tabular}

Using 5-point scale Table 4 convert as a score and score table represented by Table 5 .

All this column vectors of Table 5 represented by the formula (9). After calculating we get the normalized decision matrix represent in Table 6 . In Table 6 column two represents the PV of each criteria, determined by AHP method.

$$
r_{i j}=\frac{x_{i j}}{\sqrt{\sum_{i=1}^{4} x_{i j}^{2}}}, \forall i=1,2,3, j=1,2,3
$$

Using the formula 9 calculate weighted normalized decision matrix from Table 6 . Table 7 represents the weighted normalized decision matrix. Determine the ideal $A^{+}$and negative-ideal $A^{-}$solution using the formula according as (11) and (12). Last two column of Table 5 represents the $A^{+}$and $A^{-}$ value.

Table 6. Normalized Decision Matrix

\begin{tabular}{cccc}
\hline & \multicolumn{3}{c}{ Priority value of each Criteria } \\
\cline { 2 - 4 } Alternatives & $\boldsymbol{w}_{\mathbf{1}}=\mathbf{0 . 5 6 1 1 8 5 4 6 8}$ & $\boldsymbol{w}_{\mathbf{2}}=\mathbf{0 . 2 9 0 0 2 3 4 7 3 7}$ & $\boldsymbol{w}_{\mathbf{3}}=\mathbf{0 . 1 4 8 7 9 1 0 5 7 9}$ \\
\hline $\mathrm{A}_{1}$ & $\mathbf{C}_{\mathbf{1}}$ & $\mathbf{C}_{\mathbf{2}}$ & $\mathbf{C}_{\mathbf{3}}$ \\
\hline $\mathrm{A}_{2}$ & $r_{11}=0.59628479$ & $r_{12}=0.70710678$ & $r_{13}=0.69631062$ \\
\hline $\mathrm{A}_{3}$ & $r_{21}=0.2981424$ & $r_{22}=0.42426407$ & $r_{23}=0.17407766$ \\
\hline$r_{31}=0.74535599$ & $r_{32}=0.56568542$ & $r_{33}=0.69631062$ \\
\hline
\end{tabular}


Table 7. Weighted Normalized Decision Matrix

\begin{tabular}{cccc}
\hline \multirow{2}{*}{ Alternatives } & \multicolumn{3}{c}{ Criteria } \\
\cline { 2 - 4 } & $\mathbf{C}_{\mathbf{1}}(\mathbf{B})$ & $\mathbf{C}_{\mathbf{2}}$ (B) & $\mathbf{C}_{\mathbf{3}}(\mathbf{B})$ \\
\hline $\mathrm{A}_{1}$ & $v_{11}=0.33462636$ & $v_{12}=0.20507756$ & $v_{13}=0.10360479$ \\
\hline $\mathrm{A}_{2}$ & $v_{21}=0.16731318$ & $v_{32}=0.16406205$ & $v_{23}=0.0259012$ \\
\hline $\mathrm{A}_{3}$ & $v_{31}=0.41828295$ & $v_{2}^{+}=0.20507756$ & $v_{3}^{+}=0.10360479$ \\
\hline $\mathrm{A}^{+}$ & $v_{1}^{+}=0.41828295$ & $v_{2}^{-}=0.12304654$ & \\
\hline $\mathrm{A}^{-}$ & $v_{1}^{-}=0.16731318$ & $v_{3}^{-}=0.0259012$ & \\
\hline
\end{tabular}

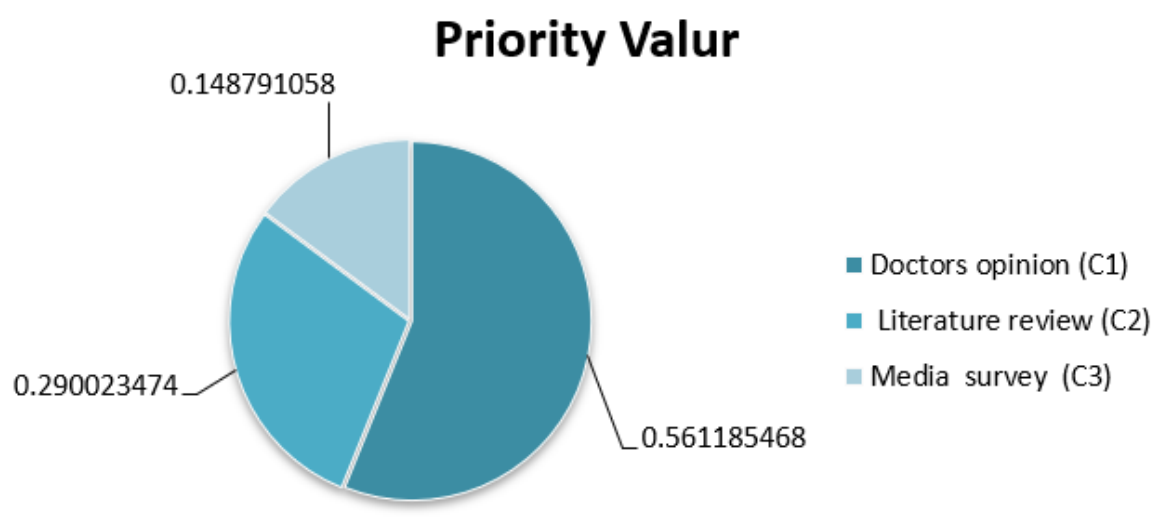

Figure 4. Result of Criteria from Fuzzy AHP

$$
\begin{gathered}
v_{i j}=w_{j} r_{i j}, \forall i=1,2,3, j=1,2,3 . \\
A^{+}=\left\{v_{1}^{+}, v_{2}^{+}, v_{3}^{+}, \ldots, v_{m}^{+}\right\}=\left\{\left(\max _{i} v_{i j} \mid j \in C_{b}\right)\right\} \\
A^{-}=\left\{v_{1}^{-}, v_{2}^{-}, v_{3}^{-}, \ldots, v_{m}^{-}\right\}=\left\{\left(\min _{i} v_{i j} \mid j \in C_{b}\right)\right\}
\end{gathered}
$$

\section{Application of GMDH}

GMDH model has been widely used to elevate the short comings of the conventional algorithms to deal with complex problems. A GMDH model is based on input and corresponding output data information. The model is developed to predict the death assessment which is proved to be helpful in the continuous monitoring of coronavirus affected peoples' death. By the use of some newly formed equations new set of independent observations are generated which will be successively very helpful.

\section{Sensitivity Analysis}

A sensitivity analysis is a mathematical formula that is used in financial modeling to calculate whether a target variable is influenced by other variables, called input variables. This study used sensitivity analysis to validate its model. The sensitivity analysis was performed with the help of a multiple input, one output, tornado method that was developed by SensIt Limited. The ranges for the input variables varied between 0 and 1 . The impact of each input was then obtained on the outputs observed, and the results were compared with the weights of the variables found from the new MCDM approach. In the next section, results are discussed.

\section{RESULT AND DISCUSSION}

In this section we discuss about our findings. These section divide into three sub-section namely result from TOPSIS 1 , result from TOPSIS, result from GMDH and result from sensitivity analysis and all this sub-section described in the section "Result from Fuzzy AHP and Fuzzy ANP", "Result from TOPSIS", "Result from GMDH" and "Result from Sensitivity Analysis" respectively. In the section "Result from Fuzzy AHP and Fuzzy ANP" discuss about the result of most significant risk factor by TOPSIS 1 . Next compare the result of TOPSIS 1 with TOPSIS (in section "Result from TOPSIS"). An optimal network is found in section "Result from GMDH" using GMDH by which we predict spread of Coronavirus. In the last section "Result from Sensitivity Analysis" tests the sensitive parameter of three considers parameters for validate our result.

\section{Result from Fuzzy AHP and Fuzzy ANP}

In the present we consider three factors as criteria namely Doctors opinion $\left(C_{1}\right)$, Literature review $\left(C_{2}\right)$ and Media survey $\left(C_{3}\right)$. Verbal contamination, Contamination due to eatables and contamination due to contact with the infected person are consider as alternatives and denoted by $A_{1}, A_{2}$ and $A_{3}$ respectively. After selection of factors then we select the most important risk factor using Fuzzy AHP for find the PV of criteria. According to the result it is clear that PV of doctors opinion (see in Figure 4) is greater than remaining two criteria. Using Fuzzy AHP result in TOPSIS 1 for selecting the most significant risk factor of spread of COVID-19. In TOPSIS 1 method $\mathrm{S}_{i}^{+}$and $\mathrm{S}_{\mathrm{i}}^{-}$ are calculated supremum distance from Table 5 using the formula according as (13) and (14). Final aggregation is calculating from $\mathrm{RC}_{\mathrm{i}}^{*}$ using formula (15). Table 8 showing all the results of $\mathrm{S}_{\mathrm{i}}^{+}, \mathrm{S}_{\mathrm{i}}^{-}$and $\mathrm{RC}_{\mathrm{i}}^{*}$. According to the results it was found that contamination due to contact with the infected person is the significant risk factor of spread of COVID-19.

$$
\begin{gathered}
S_{i}^{+}=\max \left\{\left|v_{i j}-v_{j}^{+}\right|: j=1,2,3\right\}, \forall i=1,2,3,4 \\
S_{i}^{-}=\sqrt{\sum_{j=1}^{3}\left(v_{i j}-v_{j}^{-}\right)^{2}}, \forall i=1,2,3,4 \\
R C_{i}^{*}=\frac{S_{i}^{-}}{S_{i}^{-}+S_{i}^{+}}, \forall i=1,2,3,4
\end{gathered}
$$


Table 8. RC* value for TOPSIS 1

\begin{tabular}{cccc}
\hline & $\boldsymbol{S}_{\boldsymbol{i}}^{+}$ & $\mathbf{S}_{\mathbf{i}}^{-}$ & $\mathbf{R C}_{\mathbf{i}}^{*}$ \\
\hline $\mathrm{A}_{1}$ & 0.08365659 & 0.16731318 & 0.66667 \\
\hline $\mathrm{A}_{2}$ & 0.25096977 & 0 & 0 \\
\hline $\mathrm{A}_{3}$ & 0.04101551 & 0.25096977 & 0.85953 \\
\hline
\end{tabular}

Table 9. $\mathrm{RC}^{\star}$ value for TOPSIS

\begin{tabular}{cccc}
\hline & $\mathbf{S}_{\mathbf{i}}^{+}$ & $\mathbf{S}_{\mathbf{i}}^{-}$ & $\mathbf{R C}_{\mathbf{i}}^{*}$ \\
\hline $\mathrm{A} 1$ & 0.08365659 & 0.20189264 & 0.70703269 \\
\hline $\mathrm{A} 2$ & 0.2752322 & 0 & 0 \\
\hline $\mathrm{A} 3$ & 0.04101551 & 0.2659059 & 0.86636477 \\
\hline
\end{tabular}

\section{Result from TOPSIS}

In the TOPSIS method $\mathrm{S}_{\mathrm{i}}^{+}$and $\mathrm{S}_{\mathrm{i}}^{-}$are calculated Euclidean distance from Table 7. Final aggregation is calculated (i.e., RC* value) using formula (14). According to the result it is found that TOPSIS and TOPSIS 1 give same raking of each indicator. Table 9 represents all the results of $S_{\mathrm{i}}^{+}, S_{i}^{-}$and $\mathrm{RC}_{\mathrm{i}}^{*}$ Also Table 10 represents the $\mathrm{RC}^{*}$ value error between TOPSIS and TOPSIS 1 . To find this error TOPSIS RC* value consider truth value or
Table 10. Error estimation between $\mathrm{RC}^{\star}$ value between TOSIS and TOPSIS 1

\begin{tabular}{ccc}
\hline Alternative & Absolute Error & Relative error \\
\hline $\mathrm{A} 1$ & 0.040366023 & 0.057092159 \\
\hline $\mathrm{A} 2$ & 0 & Does not Exist \\
\hline $\mathrm{A} 3$ & 0.006835937 & 0.007890368 \\
\hline
\end{tabular}

exact value because TOPSIS method already exist but TOPSIS 1 method is totally new approach so RC* value of TOPSIS 1 consider as approximate value. In this study we calculate absolute and relative error.

\section{Result from GMDH}

The GMDH model was deliberately used to minimize the error and to maximize the performance. Moreover, now a day the Neuro genetic models play a greater role in the field of research and study because of their simplicity. Here we have used the very basic equation (15) got from the artificial neural network. Figure 5 shows the comparison between observed and predicted output, Figure 6 depicts Residual, Figure 7 depicts autocorrelation and Figure 8 shows number of

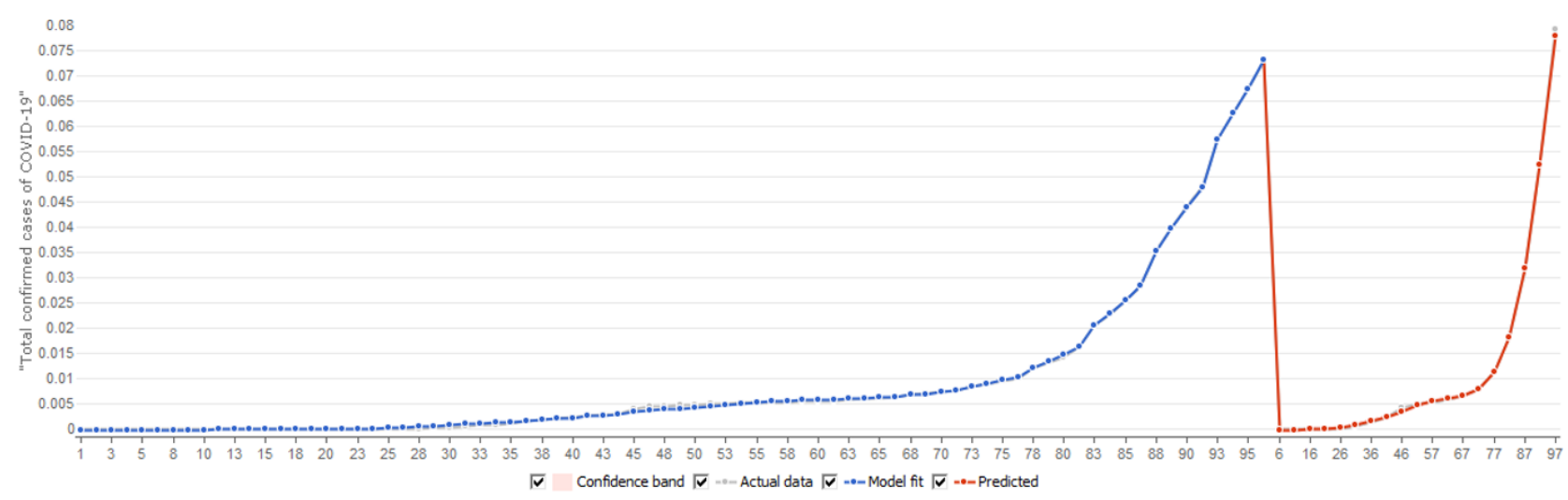

Figure 5. The comparison between observed and predicted output for model

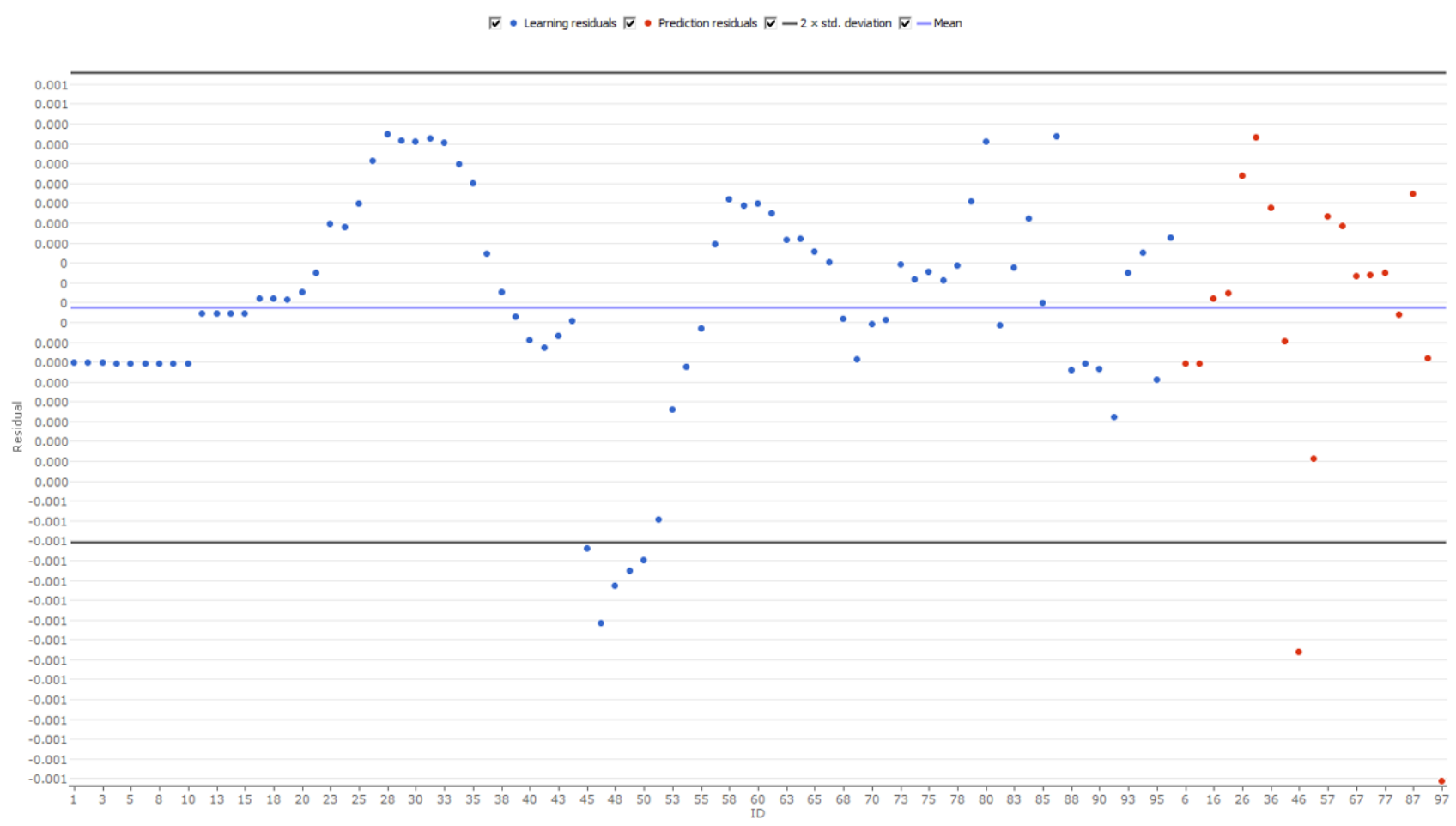

Figure 6. Residual of the proposed model 


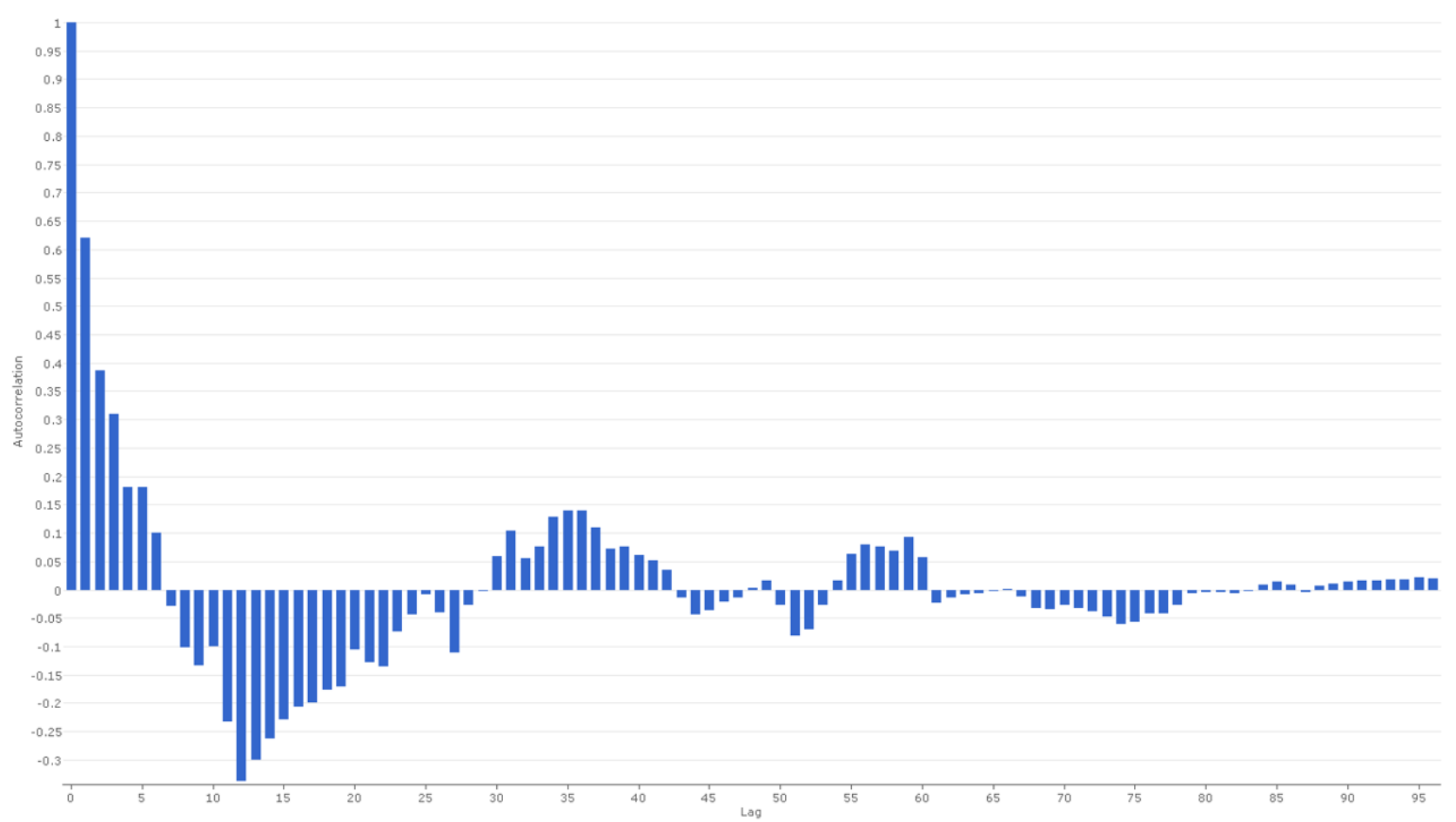

Figure 7. Autocorrelation of the proposed model

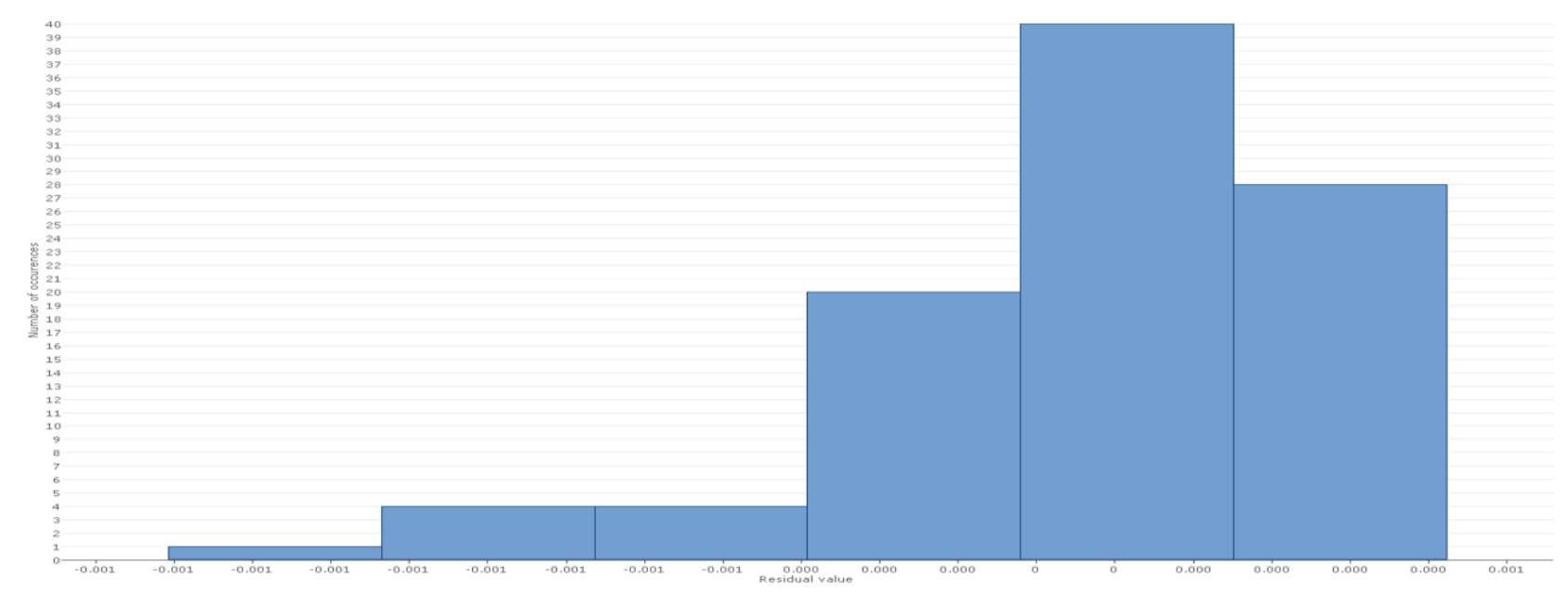

Figure 8. Number of Occurrence of the proposed model

Table 11. Absolutely Error Measure

\begin{tabular}{ccc}
\hline Postprocessed result & Model fit & Predictions \\
\hline Number of observations & 46 & 11 \\
\hline Max. Negative error & -0.00206202 & -0.00161798 \\
\hline Max. Positive error & 0.00337702 & 0.00123025 \\
\hline Mean absolute error (MAE) & 0.000860548 & 0.000864668 \\
\hline Root mean square error (RMSE) & 0.00115513 & 0.00101318 \\
\hline Residual sum & $2.68882 \mathrm{E}-16$ & -0.00466756 \\
\hline Standard deviation residuals & 0.00115513 & 0.000920044 \\
\hline Coefficient of determination ( $\mathbf{R}^{\mathbf{2}}$ ) & 0.993606 & 0.996731 \\
\hline Correlation & 0.996798 & 0.998899 \\
\hline
\end{tabular}

occurence of the proposed model. Table 11 shows absolutely Error Measurement of developed model.

$$
\begin{gathered}
Y 1=-5.34102 e-15+N 4 * 0.510204+N 3 \\
* 0.489796
\end{gathered}
$$

Where, N3 $=-1.03536 \mathrm{e}-14+\mathrm{N} 4^{\star} 1$
$\mathrm{N} 4=-0.000699931+x 1^{\star} 7.74316-x 1^{*}$ "x1,cubert" $14.2998+$ $x 1^{\wedge} 2 \star 24.9147+$ " 1 1,cubert" 0.0586169 - "x1,cubert"^2*1.12926

Here $x_{1}$ denote the data of confirmed affected case in coronavirus.

\section{Result from Sensitivity Analysis}

The sensitivity analysis was conveyed to access the sensitivity of the model with respectto its input indicators. If the priority value of the indicators be coherent with the sensitivity of the indicators used as the input to the model in the present study, then the validation of the results will be established. According to the results, the contamination due to contact with the infected person was found to have a Swing ${ }^{\wedge} 2$ value of $43.7 \%$ whereas Contamination due to eatables was found to have a Swing^2 value of $18.4 \%$. Thus, the contamination due to contact with the infected person was rated the most sensitive parameter and Contamination due to eatables the second most sensitive parameter. 
contamination due to contact with the infected person

$$
\begin{aligned}
& \text { Verbal contamination } \\
& \text { Contamination due to eatables }
\end{aligned}
$$$$
0.25
$$

Figure 9. Result of Sensitivity Analysis

The two parameters found out to be most sensitive were also found to be the two most significant parameters having the highest PV values. This indicates that these two parameters have similar sensitivity and PV which supports the selection of alternatives. It can also be concluded that from the MCDM technique, the most sensitive indicator and the least sensitive indicator has highest and lowest PV values. Figure 9 depicts the result of sensitivity analysis.

\section{CONCLUSION}

The present investigation has attempted to develop a new model for evaluation of the risk assessment of Coronavirus with the help of TOPSIS 1 and GMDH methods. The advantage of this new model will be it can objectively and cognitively analyze the spread of Coronavirus. By Doctors opinion, Literature review and Media Survey we select three risk factors of Coronavirus namely Verbal contamination, contamination through eatables, and contamination due to contact with the infected person. After collection of all factors we apply Fuzzy AHP for finding the PV of criteria. Using the PV of criteria apply TOPSIS 1 for find the best alternative. Result of TOPSIS 1 indicate that contamination due to contact with the infected person is the most significant alternative of spread of Coronavirus. Some literatures and reports also support our findings $(2,25,26)$. Next, we find an optimal network by which continuously monitoring the death from Coronavirus of infected person. In feature this TOPSIS 1 apply in energy study, manage problem and several decision-making problem. Also, these new methods apply in fuzzy environment.

\section{REFERENCES}

1. Anderson RM, Heesterbeek $\mathrm{H}$, Klinkenberg $\mathrm{D}$, Hollingsworth TD. How will country-based mitigation measures influence the course of the COVID-19 epidemic? The Lancet. 2020. https://doi.org/10.1016/S0140-6736(20) 30567-5

2. World Health Organization. Available at: https://www.who.int/

3. Xu X, Chen P, Wang J, Feng J, Zhou H, Li X, et al. Evolution of the novel coronavirus from the ongoing Wuhan outbreak and modeling of its spike protein for risk of human transmission. Science China Life Sciences, 2020;63(3):45760. https://doi.org/10.1007/s11427-020-1637-5 PMid: 32009228 PMCid:PMC7089049

4. Huang C, Wang Y, Li X, Ren L, Zhao J, et al. Clinical features of patients infected with 2019 novel coronavirus in Wuhan, China. The Lancet, 2020;395(10223):497-506. https://doi.org/10.1016/S0140-6736(20)30183-5
5. Majumder P, Majumder M, Saha AK, Sarkar K, Nath S. Real time reliability monitoring of hydro - power plant by combined cognitive decision - making technique. International Journal of Energy Research. 2019. https://doi.org/10.1002/er.4530

6. Majumder P, Saha AK, Majumder M. A mathematical approach of exploration towards extreme risk factor in cancer of optimal condition. International Journal of Pharmaceutical Sciences and Research, 2018;9(9):3732-42. https://doi.org/10.13040/IJPSR.0975-8232.9(9).3732-42

7. Majumder P, Saha AK, Majumder M. Evaluation of hydropower plants with respect to cost incurred by fuzzy decision making. Journal of civil and construction Engineering, 2016;2(3). Available at: http://matjournals.in/ index.php/JOCCE/article/view/962

8. Hwang CL, Yoon K. Methods for multiple attribute decision making. In Multiple attribute decision making (pp. 58-191). Springer, Berlin, Heidelberg. 1981. https://doi.org/ 10.1007/978-3-642-48318-9_3

9. Jahanshahloo GR, Lotfi FH, Izadikhah M. An algorithmic method to extend TOPSIS for decision-making problems with interval data. Applied mathematics and computation, 2006;175(2):1375-84. https://doi.org/10.1016/j.amc.2005. 08.048

10. Chu TC, Lin YC. An interval arithmetic based fuzzy TOPSIS model. Expert Systems with Applications, 2009;36(8):10870-6. https://doi.org/10.1016/j.eswa.2009. 01.083

11. Ozdemir H, Bird D. Evaluation of morphometric parameters of drainage networks derived from topographic maps and DEM in point of floods. Environmental Geology, 2009;56(7):1405-15. https://doi.org/10.1007/s00254-0081235-y

12. Opricovic S, Tzeng GH. Compromise solution by MCDM methods: A comparative analysis of VIKOR and TOPSIS. European journal of operational research, 2004;156(2):44555. https://doi.org/10.1016/S0377-2217(03)00020-1

13. Coronavirus Disease (COVID-19) - Statistics and Research. Available at: https://ourworldindata.org/coronavirus

14. Nariman-Zadeh N, Darvizeh A, Darvizeh M, Gharababaei H. Modelling of explosive cutting process of plates using GMDH-type neural network and singular value decomposition. Journal of Materials Processing Technology, 2002;128(1-3):80-7. https://doi.org/10.1016/ S0924-0136(02)00264-9

15. Yeh $\mathrm{CH}$, Deng $\mathrm{H}$, Chang YH. Fuzzy multicriteria analysis for performance evaluation of bus companies. European Journal of Operational Research, 2000;126(3):459-73. https://doi.org/10.1016/S0377-2217(99)00315-X

16. Lemke F, Müller JA. Self-organising data mining. Systems analysis modelling simulation, 2003;43(2):231-40. https://doi.org/10.1080/0232929031000136135 
17. Farlow SJ. Self-organizing methods in modeling: GMDH type algorithms (Vol. 54). CrC Press. 1984.

18. Nariman-Zadeh N, Darvizeh A, Jamali A, Moeini A. Evolutionary design of generalized polynomial neural networks for modelling and prediction of explosive forming process. Journal of Materials Processing Technology, 2005;164:1561-71. https://doi.org/10.1016/j.jmatprotec. 2005.02.020

19. Gang W, Wang J. Predictive ANN models of ground heat exchanger for the control of hybrid ground source heat pump systems. Applied energy, 2013;112:1146-53. https://doi.org/10.1016/j.apenergy.2012.12.031

20. Buratti C, Barelli L, Moretti E. Application of artificial neural network to predict thermal transmittance of wooden windows. Applied energy, 2012;98:425-32. https://doi.org/10.1016/j.apenergy.2012.04.004

21. Kalogirou SA. Applications of artificial neural-networks for energy systems. Applied energy, 2000;67(1-2):17-35. https://doi.org/10.1016/S0306-2619(00)00005-2

22. Sözen A, Arcaklioğlu E, Özalp M, Kanit EG. Use of artificial neural networks for mapping of solar potential in Turkey. Applied Energy, 2004;77(3):273-86. https://doi.org/ 10.1016/S0306-2619(03)00137-5
23. Kar S, Sharma KD, Maitra M. Gene selection from microarray gene expression data for classification of cancer subgroups employing PSO and adaptive K-nearest neighborhood technique. Expert Systems with Applications, 2015;42(1):612-27. https://doi.org/10.1016/ j.eswa.2014.08.014

24. Cliver DO. Control of viral contamination of food and environment. Food and Environmental Virology, 2009;1(1):3-9. https://doi.org/10.1007/s12560-008-9005-2 PMCid:PMC7090503

25. Jin YH, Cai L, Cheng ZS, Cheng H, Deng T, et al. A rapid advice guideline for the diagnosis and treatment of 2019 novel coronavirus (2019-nCoV) infected pneumonia (standard version). Military Medical Research, 2020;7(1):4. https://doi.org/10.1186/s40779-020-0233-6 PMid:32029004 PMCid:PMC7003341

26. Han Y, Yang H. The transmission and diagnosis of 2019 novel coronavirus infection disease (COVID - 19): A Chinese perspective. Journal of Medical Virology. 2020. https://doi.org/10.1002/jmv.25749 PMid:32141619 